\title{
Recurrent Bladder Adenocarcinoma
}

National Cancer Institute

\section{Source}

National Cancer Institute. Recurrent Bladder Adenocarcinoma. NCI Thesaurus. Code C4995.

A recurrence of adenocarcinoma of the bladder after a period of remission. 